УДК 903.052-903.054

https://doi.org/10.24852/2587-6112.2021.6.254.261

\title{
МЕТАЛЛОГРАФИЧЕСКИЕ ИССЛЕДОВАНИЯ АРХЕОЛОГИЧЕСКИХ ПРЕДМЕТОВ ИЗ ЖЕЛЕЗА И ПРОБЛЕМА ОЦЕНКИ ИХ СОСТОЯНИЯ СОХРАННОСТИ
}

\author{
(C) 2021 г. К.В. Доткин
}

Появление металлургии железа послужило мощным импульсом развития человечества. Нахождение новых источников железной руды, появление новых методов очистки, способов обработки и изготовления орудий труда во многом влияли на историю как локальных групп, так и всего человечества в целом. Археологические находки железных изделий показывают, на каком уровне развития находились те или иные сообщества в определенный период времени, имели ли они доступ к качественному сырью, использовали передовые или устаревшие к тому времени технологии и т.д. Металлографические исследования помогают ответить на эти вопросы. Однако, сохранность археологического железа, в большинстве случаев, оставляет желать лучшего. В связи с этим для сохранения археологических железных изделий и совершенствования методов реставрации необходимо объединение реставрационных и металлографических исследований.

Ключевые слова: реставрация, археология, металлургия, металлография, железо, сталь, сплав, сварка, ковка, технология.

\section{METALLOGRAPHIC STUDIES OF ARCHAEOLOGICAL IRON OBJECTS AND THE ISSUE OF ASSESSING THEIR PRESERVATION STATE}

\section{K.V. Dotkin}

The appearance of iron metallurgy accelerated the historical progress. The discovery of new sources of iron ore and the emergence of new purification, tool processing and manufacturing methods have largely influenced the history of all mankind. Archaeological finds of iron products indicate the development level of communities in certain periods of time, and whether they had access to high-quality raw materials, used advanced or outdated technologies at the time, etc. Metallographic studies are helping to answer these questions. However, in most cases the preservation of archaeological iron leaves much to be desired. In this regard, in order to preserve archaeological iron products and improve restoration methods, it is necessary to combine restoration and metallographic studies.

Keywords: restoration, archaeology, metallurgy, metallography, iron, steel, alloy, welding, forging, technology.

\section{Введение}

Железо - один из важнейших материалов в истории развития человечества. Появление технологии нахождения и добычи железной руды, выплавки, ковки, сварки и прочих технологических операций, связанных с черным металлом, положило начало гигантскому технологическому скачку и началу железного века. Вследствие этого закономерно, что изделия из железа, найденные во время археологических раскопок, имеют высокую информационную значимость для всестороннего исследования и понимания развития как локальных сообществ и культур, так и цивилизации в целом. При этом стоит осознавать, что при удревнении исследуемого слоя пропорционально повышается значимость железных находок - от массового материала в виде скобок, заклёпок и гвоздей XIX века до цельнолитых кинжалов кургана Аржан II. В то же время стоит отметить, что железные артефакты, наряду с высокой информативной ценностью, обладают и ещё одним общим свойством - практически всегда к археологу или реставратору железо попадает в очень плохом состоянии, зачастую близком к полному разрушению. В связи с этим реставраторам в сотрудничестве с археологами приходится прилагать очень большие усилия в целях стабилизации и консервации железных изделий, недопущения утраты ценной информации и облика исторического артефакта.

В то же время понятие «железный предмет» несколько одномерно. Традиционно в эту группу относят предметы, сделанные из железа как такового (т. н. «сырцового» или 
кричного железа, т. е. не полностью очищенного от рудных шлаков и примесей), предметы, сделанные из чугуна, и стальные изделия. Чугунные и стальные предметы уже нельзя назвать полноценно железными, поскольку материалы, из которого они сделаны, представляют собой сплавы железа и углерода, отличающиеся по процентному содержанию последнего в составе сплава. Стальные предметы также можно разделить по категориям. Это изделия из определенного сорта стали с равномерным распределением углерода; изделия из двух и более сортов железа и/или стали с разными процентными содержаниями углерода и ряд других категорий, особенность которых может быть выявлена благодаря технологическим аспектам производства - отливке, сварке, нагреву, отпуску, пакетированию и т. д. Таким образом, кажущаяся однородность и гомогенность группы предметов из железа оказывается довольно разнообразной при более близком рассмотрении. В связи с этим с целью получения более полной информации о технологиях, материалах и других аспектах изучения железных изделий необходимо привлекать смежные науки, в частности металлографию. Знания, полученные при исследовании предметов методами металлографии, а конкретно - методом микроструктурного анализа, должны помочь в вопросах изучения древней металлургии, а также в вопросах выбора и проведения реставрационных мероприятий.

\section{Основные этапы развития металлургии железа}

Определенные знания, связанные металлами вообще и с железом в частности, безусловно, появились с возникновением металлургии как таковой, началом использования этих металлов человеком. Так, в целом не вызывает сомнений у историков то, что первоначально добытое из руды железо (не «метеоритное», известное еще с каменных веков и имеющее выдающиеся характеристики) примерно в конце II тыс. до н. э. по многим параметрам уступало используемым уже длительное время меди и бронзе и не могло полностью удовлетворить запросы человека (Всемирная история в десяти томах..., 1955, с. 473). Неочищенное и необуглероженное железо было более мягким, рассыпчатым, имело более высокую, а значит и более энерго- и ресурсозатратную температуру плавления. Однако несомненно, что месторождения железных руд распространены довольно обширно, особенно в сравнении с выработкой известных источников медных руд. А методы и технологии работы с железом постепенно накапливались. Тем не менее длительное время железо использовалось совместно с бронзой, даже в сочетании в одном предмете - исследователями упоминаются своеобразные «гибридные» вещи, такие как кирки с сердцевиной из железа, покрытые слоем бронзы, наконечники стрел с железными стержнями и бронзовыми остриями и т. д., относящиеся к середине I тыс. до н. э., т. е. ко времени «уверенного» раннего железного века (Tylecote, 1992, с. 44). Также стоит отметить, что некоторое время железные изделия производили по технологии, схожей с технологией отливки предметов из бронзы. Одним из примеров подобного технологического заимствования служат находки железного кинжала из кургана Аржан II в Туве и ряд других находок скифского времени в Центральной Азии, сделанных по технологии цельной отливки (Минасян, 2014, с. 94-98).

Прогресс тем не менее шел, и постепенно обработка и производство железных изделий становились более разнообразными. Несомненным качественным сдвигом в железоделательном производстве стало открытие процесса обогащения углеродом. Принято считать, что в процессе освоения плавки в доменных печах с использованием технологии обогащения железа углеродом примерно в середине I тысячелетия до н. э. был получен чугун (железо с содержанием углерода более 2\%) (Гуляев, 1986, с. 142), который уже был отличным от кричного железа по качествам материалов и из которого впоследствии получали сталь - железо с содержанием углерода 0,25-2\% (Минасян, 2014, с. 68-72; Гуляев, 1986 , с. 142).

Дальнейшее развитие железной металлургии проходило в экспериментах и использовании новых приемов в обработке полученных железных, чугунных и стальных изделий. Предметы, для которых в качестве основного сырья мог быть использован чугун, создавались методом отливки (например, котлы и формы для отливки - кокили). Такие предметы были твердыми, довольно крепкими, но хрупкими и не предназначенными для ковки. 
Ковка была известна еще со времен бронзового века, когда медные и бронзовые орудия проковывались для придания им большей твердости и остроты на лезвиях. Сходный метод был применен и для сталей, однако свойства чистых сталей (хорошая твердость в сочетании с хрупкостью) не позволяли получать удовлетворительное по качеству изделие. В связи с этим ремесленники учились экспериментировать с уже известными и новыми способами обработки металлов (ковка в сочетании с восстановительным отжигом, отпуск, закалка) (Агрикола, 1986, с. 397), сочетать железо и сталь разных «марок», т. е. материал с разным количеством содержания углерода в составе, использовать сварку и пакетирование. Подобные эксперименты приводили к разнообразным результатам.

Одним из первых экспериментов, связанных с попыткой сочетания свойств железа и стали, были работы по кузнечной сварке углеродистой стали и железа, где из железа делалась основа, сердцевина, тело изделия (например, полотно меча или оголовок топора) и к нему кузнечным способом приваривались рабочие края (чаще - лезвия) из углеродистой стали. Подобных техник двух и более слоев насчитывается очень много, однако суть их остается одна - компенсировать недостатки одного материала другим, улучшить положительные качества (Pleiner Radomir, 2006, c. 213). Железо, как правило, мягко и легко поддаётся деформации, высокоуглеродистая сталь же тверда и при надлежащей термообработке упруга. Подобные способы и результаты сочетания слоев стали и железа в связи с характерным расположением слоев среди металлургов часто называются «пакетами», «сэндвичами» или «striped blades» (в англоязычных источниках) (Pleiner Radomir, 2006, c. 212-213; Очерки по истории..., 1997, с. 159-215). Подобные способы производства изделий с совмещенными свойствами железа и стали были распространены от стран Западной Европы до стран Дальнего Востока, хотя место происхождения этого способа остается спорным (Вендален Бехайм, 1995, с. 440).

Еще одним способом соединить свойства железа и стали в одном предмете стало скручивание и многократная перековка пластин из этих материалов. В ходе механического перемешивания материалов в теле предмета при помощи ковки эти материалы распространялись относительно равномерно, и, следовательно, равномерно распределялись их свойства. Получавшийся продукт имел характерный узорчатый рисунок на поверхности тела и лезвий. Исследователи не всегда могут прийти к единому наименованию данного вида сплава - в литературе встречаются названия «пакетная сталь», «дамасская сталь», «булатная сталь», «фаранд», «узорчатая сталь», «pattern-welded» (в англоязычных источниках) и т. д. (Вендален Бехайм, 1995, c. 441-442; Бируни, 1963, с. 230-241; Pleiner Radomir, 2006, с. 214-216; Минасян, 2014, с. 68; Очерки по истории..., 1997, с. 159-215). Стоит отметить, что два названных способа могли сочетаться в одном изделии (Pleiner Radomir, 2006, с. 217; Очерки по истории..., 1997, c. 159-215).

Что касается механических способов обработки железных изделий, то и тут разнообразие было довольно высоким (по сравнению с эпохой бронзы). При производстве бронзовых изделий в основном применялись такие операции, как нагревание до смягчения или расплава, отливка, поковка (наклеп), которым формировалась форма и лезвие, и восстановительный отжиг. Если предмет деформировался, его могли подправить поковкой и отжигом, в случае полной поломки - расплавить и отлить новое изделие. Предмет получался как бы «вечным». По этой же причине изделия преимущественно не точили абразивными способами, чтобы не допускать потерю количества металла в изделии. В целом можно сказать, что, даже несмотря на такие вещи, как неравномерное остывание расплава, дендритная ликвация, деформация от наклепа, бронзовые изделия были довольно однородными по структуре (в сравнении с изделиями из железа).

С железными предметами разнообразие приемов обработки резко увеличивается. Уникальным для железа является такой вид обработки, как обогащение углеродом. К уже названным литью, нагреванию, отжигу и поковке добавляются различные фрезерные и заточные работы при помощи абразивов, закалка и отпуск, прокат, выколотка, различные виды внешней обработки (шлифовка, чернение и др.). Большое разнообразие приобретают приемы ковки, бывшие в зача- 
точном состоянии в период бронзы, появляется кузнечная сварка (Минасян, 2014). Таким образом, разнообразие железных изделий как в плане состава изделий (железо, чугун, стали, сочетание железа и сталей), так и в плане механической обработки представляется весьма обширным, что и привело в итоге к появлению раздела металловедения - металлографии и исследований металлографическими методами археологических предметов из железа.

\section{Появление металлографии и вопросы сохранности}

Определенные знание в области металлографии появились задолго до оформления металлографии как раздела науки. Довольно обширные знания в области железоделательного производства, технологии ковки, видах и сортах железа и сталей прослеживаются в трудах Аль-Бируни (973-1048 гг. н. э.) (Бируни, 1963). Среди значительных трудов по истории развития металлургии стоит упомянуть Георгия Агриколу (1494-1555 гг. н. э.) (Агрикола, 1986) и Венделена Бехайма (1832-1900 гг. н. э.) (Вендален Бехайм, 1995). Несмотря на то что между первым упомянутым исследователем и последним прошла почти тысяча лет и заметно явное развитие технологий и знаний о рудах и минералах, многие сведения в трудах исследователей остались неизменными. Так, в вопросе изготовления «дамасской стали» всеми названными исследователями неизменно называются складывание и многократная проковка пакета, скручивание прутьев в косичку, получение волнистого узора на лезвии и т. д. Однако полноценных научных работ в вопросах изучения структуры железных изделий не проводится.

Одним из первых исследователей, которого можно назвать пионером металлографии, является российский ученый Петр Аносов (1796-1851 гг. н. э.). Он изучал метеоритное железо, внес большой вклад в изучение и раскрытие секрета технологии «дамасской стали» (Гуляев, 1986, с. 143; Металлургия железа..., 2005, с. 228). В советское время отечественная металлография (в том числе в части археологических исследований) получает значительное развитие, в том числе благодаря приоритетному развитию металлургических отраслей в Советском Союзе. Крупная фундаментальная работа по исследованию в середине XX в. проводилась Б.А. Колчиным (Колчин, 1953) и продолжалась им же и его учениками и последователями (Колчин, 1965, с. 7-27; Рындина, 1965, с. 119-128; Вознесенская, 1965, с. 129-137; Очерки по истории..., 1997). Зарубежные работы также значительны и вызывают интерес исследователя (Рындина, 1965, c. 119-122; Pleiner Radomir, 2006).

Не вдаваясь подробно во все цели и результаты названных исследований, отметим отдельно выводы, интересные нам в плане сохранности железных предметов, исследованных металлографическими методами. Практически всеми исследователями отмечается, что сохранность археологических железных находок тем выше, чем качественнее сталь использовалась при производстве (закаленная, без шлаков, чаще всего низкоуглеродистая) и чем больше технологических действий с ними было совершено (ковка, сварка, пакет, шлифовка). Исследователи пишут, что лучшая сохранность изделий наблюдается чаще всего у оружия и элементов защитного вооружения, т. е. у тех вещей, для изготовления которых использовался лучший материал и необходимо было проведение более сложных операций. Вещи бытового характера, в свою очередь, менее сложные технологически и не требующие качественного материала, такие как скобы, гвозди, бытовые ножи и топоры, элементы конских удил, клещи, щипцы, имеют более низкую сохранность. Часто отмечается спекание предметов в один в процессе археологизации (например, превращение в один конгломерат стрел в колчане). Сложность и неоднозначность восприятия их оценки сохранности, однако, состоит в том, что во многих отношениях данное наблюдение исследователей было побочным и умозрительным, определение степени коррозии и стадии сохранности не было самоцелью в научном исследовании. Также надо полагать, что исследования проводились самостоятельно, без присутствия реставраторов и, вероятнее всего, на предметах, на которых ряд реставрационных мероприятий (очистка, стабилизация) уже могли быть проведены.

В то же время в описаниях всех исследователей фактически отсутствует описание археологических изделий из «дамасской стали». Большинство описаний, как внешнего облика, так и результатов металлографического анали- 
за, представлены экземплярами частных и музейных коллекций, а также современными репликами, чего явно недостаточно для понимания процессов, которые могут произойти с археологическими предметами из «дамасской стали». Объяснений отсутствия таких изделий в археологических слоях и, соответственно, отсутствия исследований по ним можно выделить несколько. Во-первых, все исследователи истории металлургии отмечают ценность, редкость и локальность производства таких предметов. Бехайм приводит свидетельства, что меч из «дамасской стали» имелся у короля остготов Теодориха Великого (454-526 гг. н. э.), доставшийся ему от короля вандалов, в свою очередь полученный им от мавров Северной Африки и очень ценимый Теодорихом (Вендален Бехайм, 1995, с. 192). Большинство свидетельств позволяют нам сделать выводы, что из «дамасской стали» изготавливалось исключительно оружие, что показывает ценность этой стали. Оружие это необыкновенно ценилось в связи со своими исключительными свойствами. Оружие, по всей видимости, было дорогим и редким в связи со сложностью технологии, длительностью производства и, не исключено, определенной секретностью рецепта. В связи с чем можно сделать вывод, что такое оружие старались не оставлять без внимания, хранить тщательно, передавать по наследству, возможно, перековывать в случае поломки. В связи с этим дошедшие до нас образцы в музейных коллекциях обладают хорошей сохранностью и эстетичным внешним видом.

Во-вторых, отсутствие изделий из «дамасской стали» среди археологических находок может объясняться и другим фактором. В наше время частное кузнечное ремесло, в том числе с производством продукции по древним технологиям, приобрело развитие. Кузнецы, кующие изделия из «дамасской стали», а также владельцы реплик утверждают, что современный «дамасск» имеет довольно слабую коррозионную стойкость, в связи с чем требует тщательного внимания, недопущения загрязнений и ржавчины, отсутствия доступа влаги. Можно сделать косвенный вывод, что отсутствие находок из «дамасской стали» может быть связано с тем, что они не сохранились в археологическом слое и не пережили процессов археологизации. Для проверки подобной версии необходимо проведение экспериментального исследования с изготовлением изделий из «пакетов» и «дамасской стали», имитацией для них процессов археологизации и последующей проверкой степени деградации и стадий сохранности. Однако данная работа пока ждет своего заинтересованного исследователя.

В целом можно сделать некоторый вывод о том, что на сохранность археологических предметов из железа влияют не только условия залегания, кислотность или щелочность почвы, влажность и сухость слоя, а также качества сталей и железа, виды и интенсивность операций, которые были проведены с ними до начала археологизации предметов. С оценкой последнего необходимо пользоваться методами металлографии вообще и исследованием микроструктур металлов в частности.

\section{Металлография и реставрация изделий из железа}

Поскольку железные изделия в плане сохранности являются одним из самых проблемных видов археологического материала, реставраторы в значительной мере уделяли и уделяют внимания вопросам его реставрации и консервации. Однако в большинстве пособий и инструкций по реставрации археологического металла авторы в основном делают краткий очерк по истории и технологии получения железа и изделий из него, представляя всю железную продукцию в несколько обобщенном виде и, соответственно, описывая общие рекомендации для реставрации изделий их железа, чугуна, сталей разных видов (Шемаханская, 1989, с. 105-140; Шемаханская, 2015, с. 124-131; Минжулин, 1992, с. 24-25). М.В. Фармаковский пишет, что при оценке сохранности и прогнозировании реставрационных мероприятий надо учитывать особенности производства железных предметов, попавших в реставрацию, однако определенных рекомендаций по этому поводу не дает (Фармаковский, 1947, с. 66). Несколько обратная оценка видна в пособии А.В. Кирьянова - он делает обратные выводы, описывая нежелательность подвергать реставрируемый предмет нагреванию выше $100{ }^{\circ} \mathrm{C}$ во избежание изменения структуры имеющегося археологического предмета из железа (конкретно - стали, зака- 
ленной в холодной воде), что может негативно повлиять на возможный металлографический анализ (Кирьянов, 1960, с. 55).

Несомненным шагом вперед стало исследование и последующая публикация работ С.Г. Буршневой по исследованию стадий сохранности предметов из железа (Буршнева, 2019, с. 17-28), однако и в данных работах железные предметы рассматриваются как общий массив железного материала, без уточнения особенностей железных, чугунных, стальных и прочих предметов. Возможно, для улучшения оценок состояния предметов, стадий сохранности, а также прогнозирования реставрационных мероприятий стоит провести совместные исследования реставраторов и специалистов по археологической металлографии. Не стоит недооценивать также и значимость экспериментальных методов с созданием моделей и эталонов, которые при современном измерительном оборудовании и контролируемых процессах могут дать новую информацию о поведении предметов разного состава и разных технологий в процессе археологизации и последующей реставрации.

\section{Заключение}

В итоге можно сделать определенные выводы. Несмотря на относительную однородность сырья, общий массив продуктов железоделательного производства в связи с различными технологическими приемами и рецептами довольно обширен и требу- ет детального рассмотрения и классификации. Несмотря на то, что в последнее время получают развитие многие цифровые методы анализа металлов, такие как рентгенофлуоресцентный анализ, их использование в металлографических исследованиях продуктов железоделательного производства представляется несколько ограниченным, поскольку основными элементами состава таких предметов всегда будут железо и углерод в разных процентных соотношениях. В этих условиях такие методы металлографического исследования, как микроструктурный анализ (при помощи подготовки металлических шлифов), представляются актуальными и по сей день, несмотря на довольно долгую традицию его использования.

Также перспективным исследованием может стать изготовление разного рода моделей и эталонов с совмещением древних рецептов производства и современных средств измерений и фиксации результатов, проведение разного рода экспериментов на полученных моделях и сравнение результатов. Безусловно, как первые, так и вторые исследования должны проходить при участии и под руководством заинтересованных реставраторов. Полученные результаты могут оказаться интересными с точки зрения науки и улучшить методы исследования и сохранения историко-культурного наследия.

\section{ЛИТЕРАТУРА}

Агрикола Георгий. О горном деле и металлургии в двенадцати книгах. М.: Недра, 1986. 294 с.

Бируни. Собрание сведений для познания драгоценностей (Минералогия) / пер. А. М. Беленицкого; ст. и примеч. А. М. Беленицкого и Г. Г. Леммлейна. Л.: АН СССР, 1963. 521 с.

Буршнева С.Г. Реставрация археологических и этнографических предметов из железа: учебно-методическое пособие. Казань: Изд-во Казан. ун-та, 2019. 88 с.

Вендален Бехайм. Энциклопедия оружия. СПб.: АО «Санкт-Петербург оркестр», 1995. 564 с.

Вознесенская Г.А. Металл Троицкого городища // Археология. Естественные науки / Отв. ред. Б.А. Колчин. М.: Наука, 1965. С. 129-137.

Всемирная история в десяти томах, Т. 1. / Отв. ред. Е.М. Жуков. М.: Госполитиздат, 1955. 746 с.

Гуляев А.П. Металловедение. Учебник для вузов. 6-е изд., перераб и доп. М.: Металлургия, 1986. $544 \mathrm{c}$.

Кирьянов А.В. Реставрация археологических предметов. М.: АН СССР, 1960. 95 с.

Колчин А.Б. Археология и естественные науки // Археология. Естественные науки / Отв. ред. Б.А. Колчин. М.: Наука, 1965. С. 7-27.

Колчин Б.А. Черная металлургия и металлообработка в Древней Руси (Домонгольский период) / МИА. № 32. М.: Наука, 1953. 260 с.

Металлургия железа в истории цивилизации / Отв. ред. Л.Н. Белянчиков. М: МИСиС, 2005 г. 414 с. Минжулин А.И. Введение в реставрацию металлов. Киев: Нац. музей истории Украины, 1992. 100 с. 
Терехова Н.Н., Розанова Л.С., Завьялов В.И., Толмачева М.М. Очерки по истории древней железообработки в Восточной Европе. М.: Металлургия, 1997. 320 с.

Рындина Н.В. Металлография в археологии // Археология. Естественные науки / Отв. ред. Б.А. Колчин. М.: Наука, 1965. С. 119-128.

Фармаковский М.В. Консервация и реставрация музейных коллекций. М.: Красный печатник, 1947. $143 \mathrm{c}$.

Шемаханская М.С. Реставрация металла: методические рекомендации. М.: ВНИИР, 1989. 154 с.

Шемаханская М.С. Металлы и вещи. История. Свойства. Разрушение. Реставрация. М: Индрик. 2015. $288 \mathrm{c}$.

Pleiner Radomir. Iron in archaeology. Early European blacksmiths. Praha, 2006. 379 c.

Tylecote R.F. A history of metallurgy (second edition). London, 1992. 205 c.

\section{Информация об авторе:}

Доткин Константин Владимирович, студент (магистрант), Казанский (Приволжский) федеральный университет (г. Казань, Россия); dotkonstantin@yandex.ru

\section{REFERENCES}

Kir'ianov, A. V. 1960. Restavratsiia arkheologicheskikh predmetov (Restoration of Archaeological Objects). Moscow: Academy of Sciences of the USSR (in Russian).

Gulyaev, A. P. 1986. Metallovedenie (Metallurgical Science). Moscow: "Metallurgiia" Publ. (in Russian).

In Zhukov, E. V. (ed.). 1955. Vsemirnaia istoriia $v$ desiati tomakh (World History in Ten Volumes) 1. Moscow: "Gospolitizdat" Publ. (in Russian).

Voznesenskaya, G. A. 1965. In Kolchin, B. A. (ed.). Arkheologiia i estestvennye nauki (Archaeology and Natural Sciences). Moscow: "Nauka" Publ., 129-137 (in Russian).

Vendalen Beikhaim. 1995. Entsiklopediia oruzhiia (Encyclopedia of Weapons). Saint Petrsburg: "SanktPeterburg orkestr" Publ. (in Russian).

Burshneva, S. G. 2019. Restavratsiia arkheologicheskikh $i$ etnograficheskikh predmetov iz zheleza (Restoration of Archaeological and Ethnographic Iron Items). Kazan: Kazan Federal (Volga Regional) University (in Russian).

Biruni. 1963. Sobranie svedenii dlia poznaniia dragotsennostei (Mineralogiia) (Собрание сведений для познания драгоиенностей (Минералогия)). Leningrad: Academy of Sciences of the USSR (in Russian).

Georgius Agricola. 1986. O gornom dele i metallurgii v dvenadtsati knigakh (О горном деле и металлургии в двенадиати книгах). Moscow: "Nedra" Publ. (in Russian).

Kolchin, B. A. 1953. Chernaia metallurgiia i metalloobrabotka v drevnei Rusi (Domongol'skii period) (Iron and Steel Metallurgy and Metal Processing in Early Rus'(Pre-Mongol Period)). Materialy i issledovaniia po arkheologii SSSR (Materials and Research in the USSR Archaeology) 32. Moscow: "Nauka" Publ. (in Russian).

Kolchin, B. A. 1965. In Kolchin, B. A. (ed.). Arkheologiia i estestvennye nauki (Archaeology and Natural Sciences). Moscow: "Nauka" Publ., 7-27 (in Russian).

Belyanchikov, L. N. (ed.). 2005. Metallurgiia zheleza v istorii tsivilizatsii (Iron Metallurgy in the History of Civilization). Moscow (in Russian).

Minasian, R. S. 2014. Metalloobrabotka v drevnosti i srednevekov'e (Metalworking in Antiquity and the Middle Ages). SPb.: Izdatel'stvo Gosudarstvennogo

Ermitazha, 2014. Saint Petersburg: "State Hermitage Museum" Publ. (in Russian).

Minzhulin, A. I. 1992. Vvedenie v restavratsiiu metallov (Introduction to Metal Restoration). Kiev: National Museum of the History of Ukraine (in Russian).

Terekhova, N. N., Rozanova, L. S., Zav'ialov, V. I., Tolmacheva, M. M. 1997. Ocherki po istorii drevnei zhelezoobrabotki v Vostochnoi Evrope (Sketches on History of the Ancient Iron Processing in Eastern Europe). Moscow: "Metallurgiia" Publ. (in Russian).

Ryndina, N. V. 1965. In Kolchin, B. A. (ed.). Arkheologiia i estestvennye nauki (Archaeology and Natural Sciences). Moscow: "Nauka" Publ., 119-128 (in Russian).

Farmakovsky, M. V. 1947. Konservastiia i restavratsiia muzeinykh kollektsii (Conservation and Restoration of Museum Collections). Moscow: "Krasnyi pechaynik" Publ. (in Russian).

Shemakhanskaya, M. S. 1989. Restavratsiiia metalla: metodicheskie rekomendatsii (Metal Restoration: Guidelines). Moscow: All-Union Scientific Research Institute of Restoration (in Russian). 
Shemakhanskaya, M. S. 2015. Metally i veshhi. Istoriya. Svoystva. Razrushenie. Restavratsiya (Metals and Articles. History. Properties. Destruction. Restoration). Moscow: "Indrik” Publ. (in Russian).

Pleiner Radomir. 2006. Iron in archaeology. Early European blacksmiths. Praha (in English).

Tylecote, R .F. 1992. A history of metallurgy (second edition). London. (in English).

\section{About the Author:}

Dotkin Konstantin V. Kazan (Volga Region) Federal University. Kremlyovskaya St., 18, Kazan, 420000, the Republic of Tatarstan, Russian Federation; dotkonstantin@yandex.ru

Статья поступила в журнал 01.10.2021 г. Статья принята к публикации 01.12.2021 г. 